\title{
APLIKASI TES BUTA WARNA DENGAN METODE ISHIHARA PADA SMARTPHONE ANDROID
}

\author{
Randy Viyata Dhika ${ }^{1}$, Ernawati ${ }^{2}$, Desi Andreswari ${ }^{3}$ \\ 1,2,3 Program Studi Teknik Infomatika, Fakultas Teknik, Universitas Bengkulu. \\ Jl. WR. Supratman Kandang Limun Bengkulu 38371A INDONESIA \\ (telp: 0736-341022; fax: 0736-341022) \\ ${ }^{1}$ viyatadhika@gmail.com, \\ ${ }^{2}$ w_ier_na@yahoo.com, \\ 3eziandrez@yahoo.co.id
}

\begin{abstract}
Abstrak: Penelitian ini bertujuan untuk membangun suatu aplikasi tes buta warna dengan metode Ishihara pada smartphone android yang dapat digunakan oleh pengguna untuk pemeriksaan sejak dini. Penentuan jenis buta warna dilakukan dengan menghitung jumlah nilai benar yang mengimplementasikan metode Ishihara. Metode Ishihara masih menjadi salah satu pilihan utama hampir di semua negara untuk mengidentifikasi seseorang yang mengalami buta warna. Aplikasi ini dibangun dengan menggunakan bahasa pemrograman Java for Android dengan IDE Eclipse 3.5. Metode pengembangan sistem yang digunakan untuk membangun aplikasi ini adalah model sekuensial linier dan Unified Modeling Langauge (UML) sebagai perancangan sistem. Pengujian Stratified Sampling dilakukan pada user acak baik buta warna maupun berpenglihatan normal. Hasil akhir dari penelitian ini adalah terciptanya sebuah aplikasi tes buta warna yang sesuai dengan metode Ishihara yang dapat digunakan pada smartphone android dengan tingkat keberhasilan pengenalan $100 \%$.
\end{abstract}

Kata Kunci: Android Environment, Buta Warna, Ishihara, Java, UML.

Abstract: The aim of this research is to establish an application of colour blind testing with ishihara method in smartphone android which can be used by users for earlier checking. The judgment of colour blind was decided based on the correct score counting using the ishihara method. This method was still the main choice of most countries in the world in identifying someone who suffered colour blind. This application was created using Java programming language for android with IDE Eclipse 3.5. The method used in the development of the program is sequential linier model with unified modeling language (UML) as the system design. Tests Stratified random sampling was conducted on the user either color blind or sighted. The end result of this research is the creation of a color blindness test application in accordance with the Ishihara method that can be used on android smartphones with the introduction of $100 \%$ success rate.

Keywords: Android Environment, Colour Blind, Ishihara, Java, UML.

\section{PENDAHULUAN}

Penglihatan warna merupakan salah satu fungsi penglihatan yang penting dalam kehidupan sehari- hari. Pekerjaan tertentu sangat membutuhkan kemampuan pembeda warna yang baik. Akan tetapi, tidak semua orang dikaruniai kemampuan penglihatan warna yang normal. Salah satunya adalah penderita defisiensi penglihatan warna atau lebih dikenal dengan istilah buta warna.

Penderita buta warna terdapat lebih banyak pada laki-laki dibandingkan dengan perempuan, dengan persentase masing-masing 5-8\% laki-laki dan $0.5 \%$ perempuan [1]. Sebagian besar orang menganggap buta warna bukan merupakan suatu masalah yang serius, sehingga sering diabaikan meskipun dapat mengganggu pekerjaan. Beberapa masalah yang dihadapi oleh penderita buta warna yaitu:

1) Masalah sehari-hari: Kelainan buta warna dapat mengganggu aktivitas penderitanya sehari-hari. Misalnya saja dalam membedakan warna pakaian, warna lampu lalu lintas saat 
berkendara, warna simbol-simbol tertentu dan lain sebagainya.

2) Masalah bidang pendidikan: Kelainan buta warna mempengaruhi penderitanya dalam memilih program studi di universitas dan memilih karir atau pekerjaan. Beberapa pilihan program studi dan pekerjaan mensyaratkan mahasiswa atau karyawannya tidak memiliki kelainan buta warna.

3) Masalah psikologis: Diskriminasi terhadap penderita buta warna masih sering terjadi, khususnya di wilayah tertentu. Beberapa orang menganggap buta warna adalah penyakit. Ketidakmampuan dalam membedakan warna sering kali menjadi bahan ejekan/hinaan yang menyebabkan penderita buta warna merasa dikucilkan dan tidak percaya diri.

Ada banyak cara pemeriksaan yang dapat digunakan untuk mengetahui kelainan buta warna antara lain menggunakan metode Ishihara, American Optical Company, Lembaran Pseudoisochromatic, Color Pencil Discrimination, Holmgren Thompson Wool Test, Anomaloscope, dan Farnswoth Munsell. Salah satu metode yang menjadi standar dokter spesialis mata untuk melakukan tes buta warna adalah metode Ishihara. Metode Ishihara menggunakan buku yang berisikan lembaran pseudoisochromatic (plate) yang didalamnya terdapat titik-titik dengan berbagai warna dan ukuran. Titik-titik berwarna tersebut disusun sehingga membentuk lingkaran yang di dalamnya terdapat titik-titik dengan pola membentuk angka maupun garis berkelok. Plate pada buku akan mengalami perubahan warna menjadi pudar atau kusam seiring lamanya penggunaan. Tingkat kepudaran atau kekusaman warna akan mengubah keaslian plate untuk alat uji sehingga akan mempengaruhi keakuratan hasil tes.

Tingkat mobilitas dan kesibukan saat ini membuat rendahnya kesadaran dan kurangnya pengetahuan masyarakat mengenai kelainan buta warna serta melakukan tes buta warna sejak dini. Deteksi sejak dini suatu kelainan merupakan manfaat terbesar dan akan memungkinkan penanganan sejak dini pula. Bila dilihat dari jenjang pendidikan yang berlaku di Indonesia, maka salah satu yang termasuk kelompok usia dini adalah anak usia SD yang berkisar antara usia 7-11 tahun. Karena pada rentang usia tersebut, tahap perkembangan kognitif anak mampu memperlihatkan lebih dari satu dimensi secara serempak dan juga untuk menghubungkan dimensi-dimensi itu satu sama lain [2]. Pada tahap perkembangan kognitif ini, kemampuan membedakan warna juga diamati.

Melakukan pemeriksaan langsung ke dokter spesialis mata sangat jarang sekali dilakukan, sehingga bukan menjadi alternatif terbaik untuk mengetahui kelainan buta warna. Biaya yang dikeluarkan untuk melakukan pemeriksaan tersebut juga sangatlah mahal. Oleh karena itu, perlu adanya suatu inovasi tes buta warna yang dapat digunakan untuk membantu proses pemeriksaan sejak dini oleh seseorang yang dapat dilakukan dimana saja, kapan saja dan tanpa mengeluarkan biaya.

Pemanfaatan teknologi komputer secara nyata telah mempengaruhi manusia secara pribadi, keluarga, masyarakat dan organisasi. Sebelumnya, perancangan aplikasi tes buta warna dengan metode Ishihara telah dilakukan dengan berbasis komputer [3]. Pada penelitian ini telah menghasilkan aplikasi yang dapat mengidentifikasi penderita buta warna total, buta warna parsial, dan normal. Sehingga, terdapat beberapa keterbatasan yakni belum teridentifikasinya penderita protan kuat dan deutan kuat serta plate yang diujicobakan berupa image bukan dari men-generate warna. 
Smartphone merupakan handphone dengan kemampuan komputer. Smartphone saat ini banyak dijalankan dengan menggunakan sistem operasi Android. Berdasarkan hasil survey Nielson Mobile Insights Juli 2012, persentase pengguna smartphone android sebesar 51.9\% di dunia [4]. Salah satu faktor yang menjadikan pengguna memilih sebuah smartphone adalah aplikasi pendukungnya.

Aplikasi yang disediakan smartphone android dapat ditemukan dalam berbagai bidang. Dalam bidang kesehatan, salah satu aplikasi yang dibutuhkan pengguna adalah aplikasi tes buta warna. Aplikasi tersebut dapat diakses melalui smartphone dan terkoneksi ke internet untuk perubahan informasi, sehingga dapat menggunakannya tanpa batasan ruang dan waktu. Dengan memanfaatkan smartphone android, diharapkan dapat membangun aplikasi yang dapat memudahkan pemeriksaan buta warna sejak dini secara lebih mudah dan praktis.

Dari latar belakang diatas, penulis tertarik untuk melakukan penelitian dan memilih judul

“Aplikasi Tes Buta Warna Dengan Metode Ishihara Pada Smartphone Android”.

\section{LANDASAN TEORI}

\section{A. Buta Warna}

Buta warna merupakan penyakit kelainan pada mata yang ditentukan oleh gen resesif pada kromosom seks, khususnya terpaut pada kromosom $\mathrm{X}$ atau kondisi ketika sel-sel retina tidak mampu merespon warna dengan semestinya. Istilah buta warna atau colour blind sebetulnya salah pengertian dan menyesatkan, karena seorang penderita buta warna tidak buta terhadap seluruh warna. Akan lebih tepat bila disebut gejala defisiensi daya melihat warna tertentu saja atau colour vision deficiency [1].

\section{B. Klasifikasi Buta Warna}

Masalah yang dirasakan oleh penderita buta warna adalah kesulitan mengenali warna tertentu atau tidak bisa melihat warna tertentu. Tingkatan buta warna dapat diklasifikasikan menjadi 3 jenis yaitu [5]:

1) Anomali Trikomat: Suatu keadaan dimana tiga jenis sel kerucut tetap ada, tetapi satu diantaranya tidak normal atau tidak berfungsi dengan baik, sehingga penderita akan mengalami kesulitan membedakan nuansa warna tertentu. Jenis buta warna ini sering dialami oleh kebanyakan orang yaitu:

a. Protanomali (lemah merah)

Terjadi karena sel kerucut warna merah tidak berfungsi dengan baik, sehingga penderita kurang sensitif atau kesulitan mengenali warna merah dan perpaduannya.

b. Deuteranomali (lemah hijau)

Terjadi karena sel kerucut warna hijau tidak berfungsi dengan baik, sehingga penderita kurang sensitif atau kesulitan mengenali warna merah dan perpaduannya.

c. Tritanomali (lemah biru)

Terjadi karena sel kerucut warna biru tidak berfungsi dengan baik, sehingga penderita kurang sensitif atau kesulitan mengenali warna merah dan perpaduannya.

2) Dikhromat: keadaan ketika satu dari tiga sel kerucut tidak ada. Ada tiga klasifikasi dikromasi yaitu:

a. Protanopia (buta warna merah)

Protanopia terjadi karena sel kerucut warna merah tidak ada sehingga tingkat kecerahan warna merah atau perpaduannya menjadi berkurang. Penglihatan penderita protanopia akan tampak seperti pada Gambar 1 dibawah ini: 


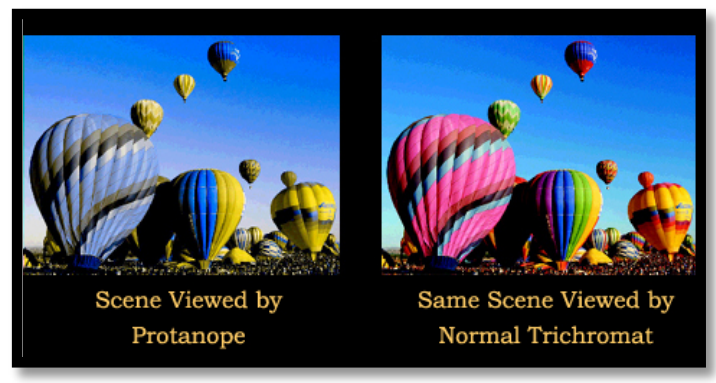

Gambar 1. Protanopia [5]

b. Deuteranopia (buta warna hijau)

Deuteranopia terjadi karena sel kerucut warna hijau tidak ada sehingga tingkat kecerahan warna hijau atau perpaduannya menjadi berkurang. Penglihatan penderita deuteranopia akan tampak seperti pada Gambar 2 dibawah ini:

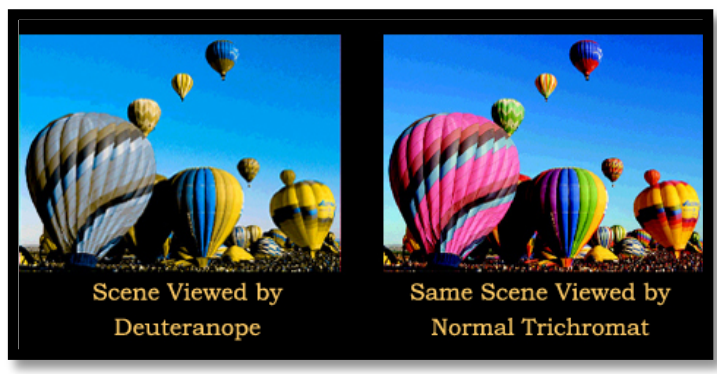

Gambar 2. Deuteranopia

c. Tritanopia (buta warna biru)

Tritanopia terjadi karena sel kerucut warna biru tidak ada sehingga tingkat kecerahan warna biru atau perpaduannya menjadi berkurang. Penglihatan penderita Tritanopia akan tampak seperti pada Gambar 3 dibawah ini:

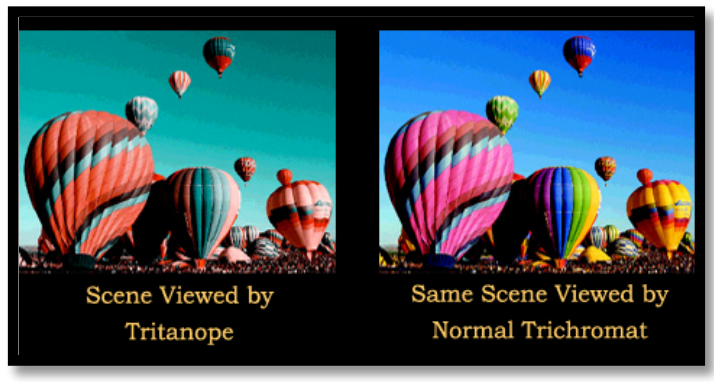

Gambar 3 Tritanopia

3) Monokhromat: Monokromasi adalah kondisi retina mata yang mengalami kerusakan total dalam merespon warna. Monokromasi ditandai dengan hilangnya atau berkurangnya semua penglihatan warna, sehingga yang terlihat hanya putih dan hitam yang mampu diterima retina. Jenis buta warna ini prevalensinya sangat jarang. Penglihatan penderita monokromasi akan tampak seperti Gambar 4 dibawah ini:

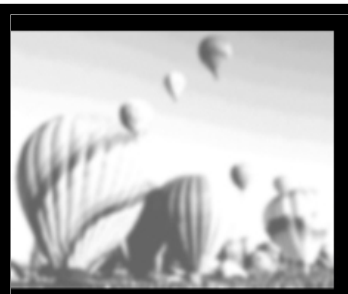

Scene Viewed by

Rod Monochromat

Gambar 4. Monokhromat
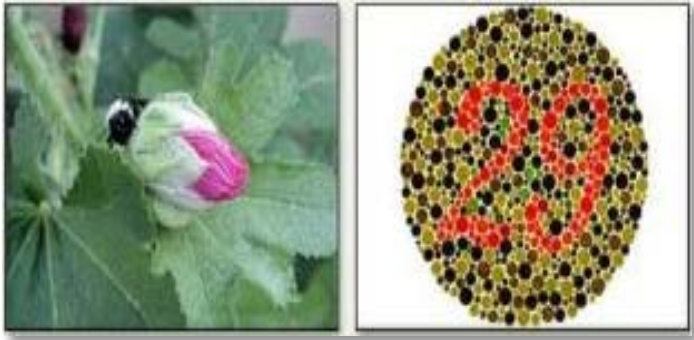

Gambar 5. Penglihatan Mata Normal
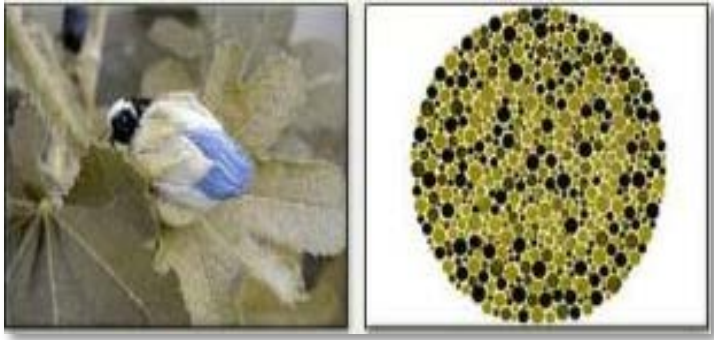

Gambar 6 Penglihatan Mata Protanopia
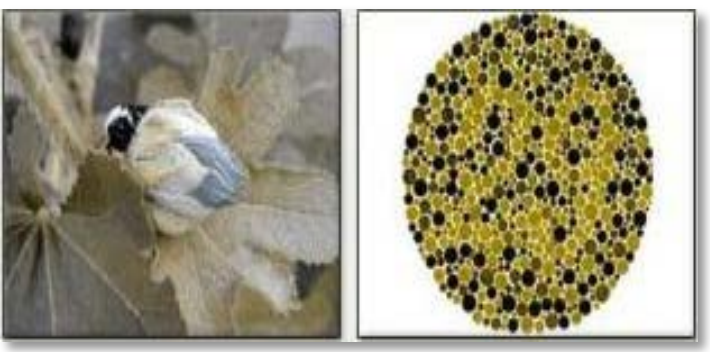

Gambar 7. Penglihatan Mata Deuteranopia 


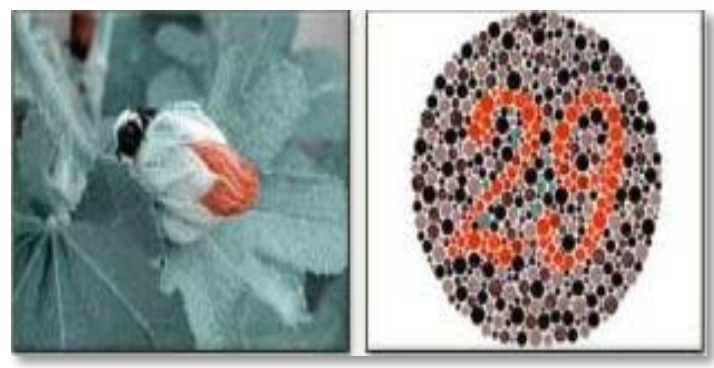

Gambar 8. Penglihatan Mata Tritanopia

\section{Metode Ishihara}

Tes Ishihara dikembangkan oleh Dr. Shinobu Ishihara pada tahun 1917, hingga saat ini metode tes Ishihara masih menjadi salah satu pilihan utama hampir di semua negara untuk mengidentifikasi seseorang yang mengalami buta warna. Tes metode Ishihara adalah tes yang digunakan untuk mendeteksi gangguan persepsi warna, berupa tabel warna khusus berupa lembaran pseudoisokromatik (plate) yang disusun oleh titiktitik dengan kepadatan warna berbeda yang dapat dilihat dengan mata normal, tapi tidak bisa dilihat oleh mata yang mengalami defisiensi sebagian warna.

Plate adalah warna primer dengan dasar warna yang hampir sama atau abu-abu. Tes Ishihara secara relatif dapat dipercaya dalam membedakan antara defisit (lemah) warna merah dan defisit (lemah) warna hijau. Tes buta warna Ishihara terdiri dari lembaran yang di dalamnya terdapat titik-titik dengan berbagai warna dan ukuran. Titik-titik berwarna tersebut disusun sehingga membentuk lingkaran yang didalamnya terdapat titik-titik dengan pola membentuk angka maupun garis berkelok. Warna titik-titik itu dibuat sedemikian rupa sehingga orang buta warna tidak akan berhasil melihat angka maupun garis yang ada.

Di ruangan dengan penerangan yang cukup, pasien diminta melihat plate dan diminta untuk mengidentifikasi atau menyebutkan angka atau mengikuti jejak garis yang terdapat pada titik-titik warna berbentuk lingkaran tidak lebih dari 10 detik. Pada orang normal, di dalam lingkaran akan tampak angka atau pola garis tertentu. Tetapi pada orang buta warna, yang tampak dalam lingkaran tersebut akan berbeda seperti yang dilihat oleh orang normal atau ia tidak bisa melihat angka maupun pola garis yang ada. Hasil tes seseorang akan dibandingkan dengan kunci jawaban, selanjutnya diidentifikasi dan diklasifikasikan untuk menentukan tingkatan buta warnanya [5].

Pembagian fungsionalitas 21 plate Ishihara yang digunakan pada tes buta warna pada umumnya ditunjukkan pada Tabel 1.

Tabel 1 Fungsi Ishihara

\begin{tabular}{|c|c|}
\hline \multicolumn{2}{|c|}{ FUNGSI ISHIHARA } \\
\hline Tipe Desain & Pendahuluan \\
\hline $\begin{array}{l}\text { Angka pada } \\
\text { plate Ishihara }\end{array}$ & 12 \\
\hline Fungsi & $\begin{array}{l}\text { plate dapat dibaca oleh orang yang } \\
\text { berpenglihatan normal dan buta } \\
\text { warna. }\end{array}$ \\
\hline Tipe Desain & Pentransformasian \\
\hline $\begin{array}{l}\text { Angka pada } \\
\text { plate Ishihara }\end{array}$ & $8,6,29,57,5,3,15,74$ \\
\hline Fungsi & $\begin{array}{l}\text { Angka pada plate yang terlihat } \\
\text { dengan orang berpenglihatan } \\
\text { normal berbeda dengan angka } \\
\text { yang terlihat pada orang yang } \\
\text { berpenglihatan lemah terhadap } \\
\text { warna merah-hijau. }\end{array}$ \\
\hline Tipe Desain & Penghilangan \\
\hline $\begin{array}{l}\text { Angka pada } \\
\text { plate Ishihara }\end{array}$ & $2,6,97,45,5,7,16,73$ \\
\hline Fungsi & $\begin{array}{l}\text { Angka pada plate terlihat oleh } \\
\text { orang yang berpenglihatan } \\
\text { normal, tetapi tidak terlihat oleh } \\
\text { orang dengan kelemahan } \\
\text { penglihatan terhadap warna } \\
\text { merah-hijau. }\end{array}$ \\
\hline Tipe Desain & Pengklasifikasian \\
\hline $\begin{array}{l}\text { Angka pada } \\
\text { plate Ishihara }\end{array}$ & $26,42,35,96$ \\
\hline Fungsi & $\begin{array}{l}\text { Ada dua angka pada tiap plate } \\
\text { Ishihara tipe ini. } \\
\text { Protan hanya dapat melihat angka } \\
\text { di sebelah kanan. } \\
\text { Deutan hanya dapat melihat angka } \\
\text { di sebelah kiri. } \\
\text { Catatan: Jika kedua angka terlihat, } \\
\text { tipe protan lemah akan lebih jelas } \\
\text { melihat angka sebelah kanan } \\
\text { dibandingkan angka sebelah kiri, } \\
\text { dan sebaliknya untuk tipe deutan. }\end{array}$ \\
\hline
\end{tabular}




\section{METODOLOGI}

Langkah-langkah yang dilakukan dalam penelitian ini adalah:

1) Studi Pustaka: Studi literatur dilakukan dengan cara mengumpulkan informasi-informasi yang dijadikan sebagai acuan perancangan aplikasi tes buta warna, dan metode Ishihara.

2) Wawancara: Wawancara yaitu mengumpulkan data dengan cara tanya jawab langsung terhadap objek tempat melakukan penelitian yaitu di RS A.K. Gani Palembang. Pada penelitian ini, peneliti melakukan wawancara kepada dr. Nirwan Arif, Sp.M sebagai dokter spesialis mata.

\section{ANALISIS DATA DAN PERANCANGAN}

Perkembangan teknologi memunculkan berbagai inovasi yang mengarah kepada tujuan untuk mempermudah aktifitas manusia serta membantu orang yang memiliki kekurangan. Contohnya, teknologi text-to-speech merupakan salah satu teknologi untuk membantu penyandang tunanetra. Di lain pihak, teknologi speech-to-text menjadi salah satu teknologi yang dapat membantu penyandang tunarungu. Masih banyak lagi program atau perangkat-perangkat yang dapat membantu para penyandang cacat dan kekurangan lainnya. Saat ini masih jarang sekali teknologi yang secara efektif dan efisien dapat digunakan untuk membantu penyandang buta warna.

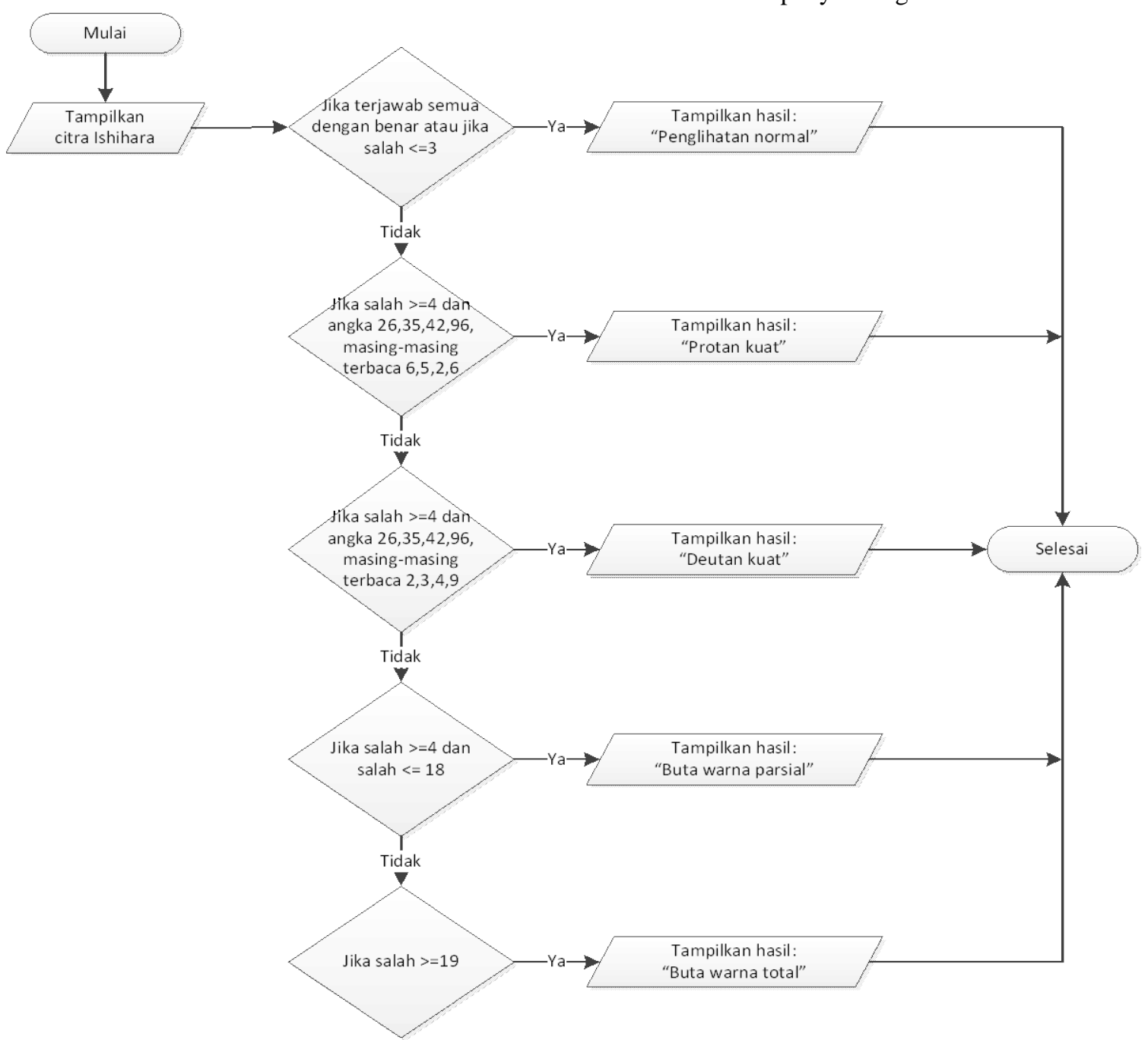

Gambar 10. Alur Metode Ishihara 
Dengan tingkat mobilitas dan kesibukan saat ini membuat alat yang digunakan untuk pemeriksaan tes buta warna menjadi hal yang kurang diminati sehingga bukan menjadi alternatif terbaik sebagai sarana untuk melakukan pemeriksaan. Salah satu cara untuk mengatasi hal tersebut maka ada baiknya jika dijadikan suatu aplikasi tes buta warna. Aplikasi tersebut dapat digunakan untuk membantu proses pemeriksaan sejak dini oleh penderita buta warna yang dapat dilakukan dimana saja dan kapan saja.

Analisis sistem adalah penelitian atas sistem yang telah ada dengan tujuan untuk merancang sistem yang baru atau diperbarui. Tahap analisis sistem ini merupakan tahap yang sangat kritis dan sangat penting, karena kesalahan di dalam tahap ini akan menyebabkan juga kesalahan di tahap selanjutnya.

Plate Ishihara yang biasa digunakan memiliki warna dominan antara merah dan hijau sehingga hanya dapat digunakan untuk mengetahui buta warna parsial terhadap warna merah-hijau. Buta warna parsial terhadap warna biru-kuning akan sulit diketahui dari tes ini karena plate Ishihara sedikit sekali menggunakan warna biru dan kuning. Dengan demikian, fitur tes buta warna yang diimplementasikan pada smartphone android ini, hanya akan menentukan jenis karakter penglihatan terhadap warna tipe protan kuat (kelemahan penglihatan terhadap warna merah), deutan kuat (kelemahan penglihatan terhadap warna hijau), buta warna total, normal, dan apabila kondisi di atas tidak ada yang terpenuhi atau dengan kata lain ada kemungkinan pengguna adalah tipe protan lemah, deutan lemah, atau tritan (kelemahan terhadap warna biru), maka aplikasi akan mengenali pengguna sebagai buta warna parsial.
Perancangan aplikasi tes buta warna ini menggunakan 7 macam model diagram UML, yaitu use case diagram, activity diagram, sequence diagram, class diagram, object diagram, state chart diagram dan collaboration diagram.

Use case diagram digunakan untuk menggambarkan interaksi antara pengguna sistem (actor) dengan sistem atau kasus, dan disesuaikan dengan langkah-langkah yang telah ditentukan. Aktor menggambarkan orang, sistem atau external entita/stakeholder yang menyediakan atau menerima informasi dari sistem. Berikut use case diagram dari sistem yang dibangun:

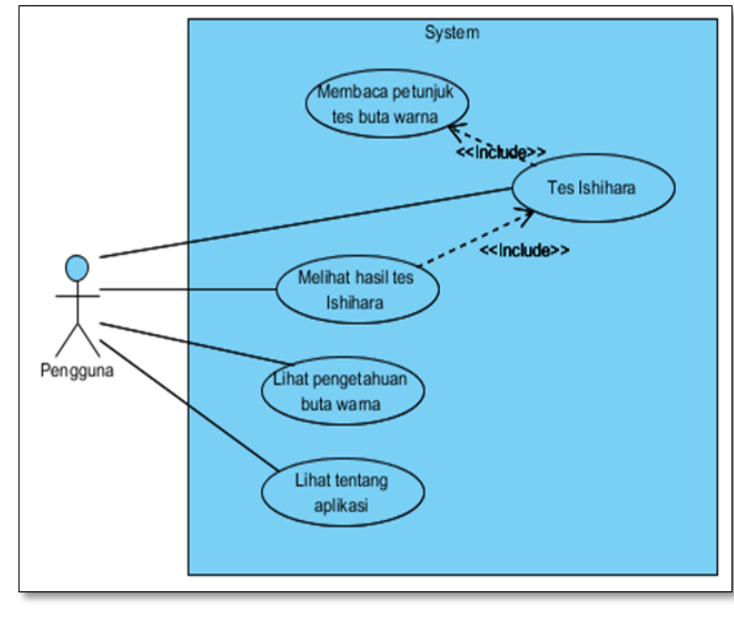

Gambar 11. Use Case Diagram

\section{HASIL DAN PEMBAHASAN}

\section{A. Hasil Pengujian Penerapan Metode Ishihara} Pada Aplikasi Tes Buta Warna

Ishihara merupakan sebuah metode yang digunakan untuk mengidentifikasi buta warna. Metode Ishihara ini terdiri dari Plate yang tersusun dari warna primer dengan dasar warna yang hampir sama atau abu-abu, membedakan antara lemah warna merah dan lemah warna hijau, titiktitik dengan berbagai warna dan ukuran, dan titiktitik dengan pola membentuk angka. Tabel 2 merupakan hasil pengujian penerapan metode Ishihara pada aplikasi. 
Tabel 2 Pengujian Penerapan Metode Ishihara pada Aplikasi

\begin{tabular}{|l|l|c|l|}
\hline No. & Kriteria Ishihara & Berhasil & Keterangan \\
\hline 1 & $\begin{array}{l}\text { Plate yang tersusun } \\
\text { dari warna primer } \\
\text { dengan dasar warna } \\
\text { yang hampir sama } \\
\text { atau abu-abu }\end{array}$ & $\sqrt{ }$ & $\begin{array}{l}\text { Semua plate } \\
\text { tes Ishihara }\end{array}$ \\
\hline 2 & $\begin{array}{l}\text { Dapat membedakan } \\
\text { antara lemah merah } \\
\text { dan lemah hijau }\end{array}$ & $\sqrt{ }$ & $\begin{array}{l}\text { Plate } \\
\text { 26,35,42,96 }\end{array}$ \\
\hline 3 & $\begin{array}{l}\text { Titik-titik dengan } \\
\text { berbagai warna dan } \\
\text { ukuran }\end{array}$ & $\sqrt{ }$ & $\begin{array}{l}\text { Semua plate } \\
\text { tes Ishihara }\end{array}$ \\
\hline 4 & $\begin{array}{l}\text { Titik-titik dengan } \\
\text { membentuk pola } \\
\text { angka }\end{array}$ & $\sqrt{ }$ & $\begin{array}{l}\text { Semua plate } \\
\text { tes Ishihara }\end{array}$ \\
\hline
\end{tabular}

Pengujian penerapan metode ishihara pada aplikasi dilakukan selama 10 detik untuk setiap plate dan dengan menginputkan angka jawaban pada textfield sebanyak 21 plate.

\section{B. Hasil Pengujian Kebenaran Aplikasi dan \\ Pemeriksaan Sejak Dini akan Buta Warna}

Untuk mengetahui kebenaran pada aplikasi yang telah dibuat menghasilkan luaran yang sesuai dengan rancangan, maka perlu dilakukan perbandingan antara hasil output proses pada sistem dengan perhitungan manual.

Jika luaran yang dihasilkan pada perhitungan secara manual berbeda dengan output pada aplikasi, maka dapat disimpulkan bahwa terjadi kesalahan pada proses implementasi sehingga akan dilakukan perbaikan kembali. Namun, jika output yang dihasilkan pada perhitungan aplikasi dan manual sama, maka dapat disimpulkan bahwa proses implementasi tersebut telah berhasil.

Metode pengujian dilakukan dengan mengambil sampel sebanyak 50 pengguna untuk melakukan tes buta warna hasil implementasi aplikasi tes buta warna. Untuk menguji tujuan penelitian yaitu pemeriksaan sejak dini akan buta warna, pemilihan sampel yang dilakukan dengan metode stratified sampling yang dibagi ke dalam 5 kategori terdiri dari usia pendidikan SD (6-12 tahun) sebanyak 10 sampel, usia pendidikan SMP (13-15 tahun) sebanyak 10 sampel, usia pendidikan SMA (16-18 tahun) sebanyak 10 sampel, usia pendidikan Perguruan Tinggi (19-22 tahun) sebanyak 10 sampel, dan usia lebih dari sama dengan 23 tahun sebanyak 10 sampel.

Dari 50 sampel yang diujicobakan dengan aplikasi tes buta warna, terdapat 2 sampel yang teridentifikasi buta warna parsial dan sisanya 48 sampel teridentifikasi berpenglihatan normal. Semuanya memiliki hasil yang sama dengan hasil output secara manual, sehingga dapat dikatakan bahwa aplikasi tes buta warna telah berhasil diimplementasikan kebenarannya dan pemeriksaan sejak dini akan buta warna (keakuratan 100\%).

\section{Hasil Pengujian Aplikasi Tes Buta Warna pada OS Android}

Pengujian dilakukan untuk menguji performa sistem dari aplikasi tes buta warna yaitu implementasi aplikasi pada 2 versi OS Android yang berbeda. Aplikasi tes buta diujicobakan pada OS Android Gingerbread 2.3 dan OS Android Ice Cream Sandwich 4.0 menggunakan resolusi layar 480x800 piksel. Berikut ini akan ditampilkan hasil pengujian aplikasi tes buta warna pada smartphone android:

1. Samsung Galaxy W (OS Android
Gingerbread 2.3)

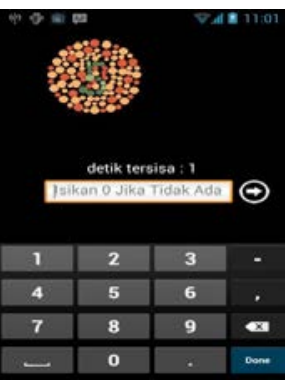

Gambar 15. Tes Ishihara pada Samsung Galaxy W

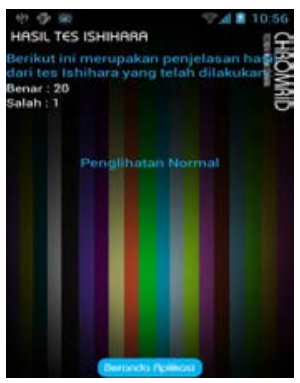

Gambar 16. Hasil Tes Ishihara pada Samsung Galaxy W 
2. Advan Vandroid S5 (OS Android Ice Cream Sandwich 4.0)

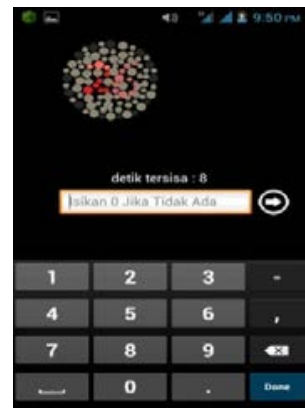

Gambar 17. Tes Ishihara pada Advan Vandroid S5

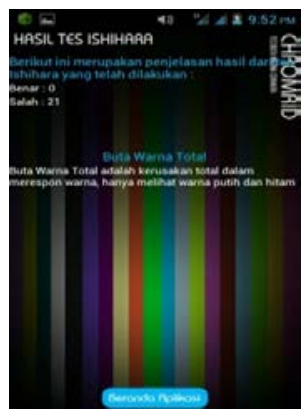

Gambar 18. Hasil Tes Ishihara pada Advan Vandroid S5
Dari pengujian diatas disimpulkan bahwa aplikasi tes buta warna ini dapat diimplementasikan pada 2 versi OS Android yang berbeda yaitu Gingerbread 2.3 dan Ice Cream Sandwich 4.0. Dengan OS minimal Android Gingerbread 2.3 dan resolusi minimal 480x800 piksel.

\section{KESIMPULAN}

Berdasarkan analisa perancangan sistem, implementasi dan pengujian sistem, maka dapat disimpulkan bahwa:

1. Penelitian ini telah berhasil menghasilkan aplikasi tes buta warna pada smartphone android yang dapat digunakan oleh pengguna untuk pemeriksaan buta warna sejak dini serta mengidentifikasi penderita protan kuat dan deutan kuat yang dibangun dengan menggunakan bahasa pemrograman Java for Android dengan IDE Eclipse 3.5.

2. Metode Ishihara yang diimplementasikan pada smartphone android memberikan hasil yang optimal berdasarkan 50 sampel yang diujicobakan dengan aplikasi tes buta warna terdapat 2 sampel yang teridentifikasi buta warna parsial dan sisanya 48 sampel teridentifikasi berpenglihatan normal.

Semuanya memiliki hasil yang sama dengan hasil output secara manual.

3. Dalam pengukuran uji kelayakan sistem, didapatkan rata-rata untuk 5 kategori yang terdiri dari usia pendidikan SD, SMP, SMA, Perguruan Tinggi, dan usia $>=23$ tahun dari segi tampilan "BAIK", dari segi kemudahan pengguna "BAIK", dan dari segi kinerja sistem "BAIK".

\section{SARAN}

1. Mengembangkan aplikasi yang dapat digunakan pada perangkat bergerak lainnya yang mempunyai sistem operasi tersendiri seperti iphone dan blackberry.

2. Aplikasi ini dapat terus dikembangkan lebih lanjut dalam hal metode pemeriksaan, ke depannya diharapkan untuk dapat menggunakan metode pemeriksaan selain metode Ishihara.

\section{REFERENSI}

[1] I. Akbari and dkk, "Persilangan Gen Terpaut," Universitas Sebelas Maret, Surakarta, 2011.

[2] E. Syaodih, "Perkembangan Kognitif Anak," 8 Agustus 2012. [Online]. Available: http://file.upi.edu/Direktori/FIP/JUR._PGTK/ 196510011998022ERNAWULAN_SYAODIH/ perk_kognitif_anak.pdf. [Accessed 25 Oktober 2013].

[3] R. Widianingsih and dkk, "Aplikasi Tes Buta Warna Dengan Metode Ishihara Berbasis Komputer," Jurnal Informatika Mulawarman, pp. 36-41, 2010.

[4] Nielsen, "Smartphones Account for Half of all Mobile Phones, Dominate New Phone Purchases in the US," 29 Maret 2012. [Online]. Available: http://blog.nielsen.com/nielsenwire/online_mobile/ smartphones-account-for-half-of-all-mobile-phonesdominate-new-phone-purchases-in-the-us/. [Accessed 4 Februari 2013].

[5] A. N. Rokhim, Mengenal Tes Buta Warna, Yogyakarta: Rona Publishing, 2012. 